\title{
PEGylated arginine deiminase can modulate tumor immune microenvironment by affecting immune checkpoint expression, decreasing regulatory $T$ cell accumulation and inducing tumor $T$ cell infiltration
}

\author{
Elena Brin ${ }^{1}$, Katherine Wu${ }^{1}$, Hsin-Tze Lu ${ }^{1}$, Yudou He ${ }^{1}$, Zhaoming Dai ${ }^{2}$ and Wei He ${ }^{1,2}$ \\ ${ }^{1}$ Polaris Pharmaceuticals, San Diego, CA, USA \\ ${ }^{2}$ DesigneRx Pharmaceuticals, Shanghai, China \\ Correspondence to: Elena Brin, email: ebrin@polarispharma.com
}

Keywords: arginine deiminase, TILs, Treg, immunomodulation, $P D-L$

Received: November 08, $2016 \quad$ Accepted: July 16, 2017

Published: July 26, 2017

Copyright: Brin et al. This is an open-access article distributed under the terms of the Creative Commons Attribution License 3.0 (CC BY 3.0), which permits unrestricted use, distribution, and reproduction in any medium, provided the original author and source are credited.

\section{ABSTRACT}

PEGylated arginine deiminase (ADI-PEG 20) is being investigated in clinical studies in arginine auxotrophic cancers and is well-tolerated. The anti-tumor properties of ADI-PEG 20 have been extensively investigated - ADI-PEG 20 inhibits the growth of auxotrophic cancers in vitro and in vivo - however, its impact on immune cells is largely unknown. Here we report the potential impact of ADI-PEG 20 on the tumor immune microenvironment. ADI-PEG 20 induced immunosuppressive programmed death-ligand 1 expression on some cancer cells in vitro, but the magnitude of the increase was cell line dependent and in most relatively small. Using healthy donor human peripheral blood mononuclear cells (PBMCs) we discovered that when present during initiation of T cell activation (but not later on) ADI-PEG 20 can inhibit their differentiation after early activation stage manifested by the expression of CD69 marker.

In vivo, ADI-PEG 20 induced tumor T-cell infiltration in a poorly immunogenic syngeneic mouse melanoma B16-F10 model and reduced its growth as a single agent or when combined with anti-PD-1 mAb. It was also effective by itself or in combination with anti-PD-L1 mAb in CT26 colon carcinoma syngeneic model.

\section{INTRODUCTION}

Unlike normal tissues many tumors cannot synthetize arginine from citrulline due to deficiency of the key urea cycle enzyme, argininosuccinate synthetase 1 (ASS1) and this arginine auxotrophy phenomenon has been explored with anti-cancer treatments that deplete arginine [1-7]. PEGylated arginine deiminase (ADIPEG 20) depletes the external supply of arginine by converting it to citrulline and ammonia. ADI-PEG 20 is being investigated in the clinic for the treatment of patients with tumor deficiency in ASS1. ASS1 is required for the conversion of citrulline to arginine [8]. ADI-PEG 20 has been demonstrated to be well-tolerated and has shown promise in clinical studies [1-7].

Arginine is used in a number of metabolic pathways, including those involved in modulating immune responses.
It is a substrate for arginase and iNOS, enzymes that play important roles in immune cell regulation [9-15]. T cells need arginine for proliferation, $\mathrm{T}$ cell receptor (TCR) expression, and development of memory [9-12].

While arginine deprivation has been shown to impede proliferation and cell cycle progression of activated $T$ cells in vitro [16-20] this effect can be reversed by addition of citrulline [16-18]. Similarly, prolonged loss of CD3 and T cell inhibition was induced in vitro by macrophages expressing arginase I (converts arginine to ornithine) and not those producing NOS2 (converts arginine to citrulline and NO) [21]. Lack of arginine induces increased transcription and stability of RNAs encoding a multi-amino acid transport system including CAT-1 which increases transport of cationic amino acids into the cell [22-25]. Under low arginine conditions $\mathrm{T}$ cells increase citrulline uptake and upregulate 
expression of ASS1 which converts citrulline into arginine $[16,17,26]$. Therefore, while conversion of arginine into ornithine by arginase can lead to immunosuppression in the tumor microenvironment [17] conversion of arginine into citrulline may have a different outcome.

The anti-tumor properties of ADI-PEG 20 have been extensively investigated [3-7, 27-29], however, its impact on immune cells is largely unknown. Therefore, we have investigated potential implications of ADIPEG 20 treatment on tumor immune surveillance. We analyzed the effect of ADI-PEG 20 on T cell subsets in healthy donor peripheral blood mononuclear cells (PBMCs) under resting and activation conditions. ADIPEG 20 did not affect resting $\mathrm{T}$ cells. Under stimulation conditions while allowing CD69 upregulation ADIPEG 20 inhibited further $\mathrm{T}$ cell activation including expression of checkpoint inhibitor molecules and accumulation of cells with regulatory $\mathrm{T}$ cells (Treg) markers (CD3+CD4+CD25+FoxP3+CTLA4+). When ADI-PEG 20 treatment was initiated more than a day after stimulation it did not affect $\mathrm{T}$ cells.

Immune checkpoint inhibitor programmed death ligand 1 (PD-L1) can dampen immune responses and its expression on tumor cells can be affected by various factors. We found that ADI-PEG 20 upregulates PD-L1 in a number of cancer cell lines in vitro, but the magnitude of the increase is cell line dependent and in the majority of the studied cell lines it was rather small.

We investigated ADI-PEG 20 efficacy in syngeneic models by itself and in combination with anti-mPD-1 and mPD-L1 antibodies. In a poorly immunogenic syngeneic B16-F10 melanoma mouse model ADI-PEG 20 treated animals had a large $\mathrm{T}$ cell infiltrate while, as expected, very few $\mathrm{T}$ cells were found in tumors from non-treated controls. ADI-PEG 20 reduced tumor growth in both B16-F10 and CT26 models and trended to be additive with anti-mPD-1 and mPD-L1 antibodies.

\section{RESULTS}

\section{Effect of ADI-PEG 20 on PD-L1 expression in ASS1-low cancer cell lines}

We have selected 16 ASS1-low cancer cell lines as well as a control ASS1-high cell line (N87) to investigate the effect of ADI-PEG 20 treatment on the expression of the well-characterized immune checkpoint inhibitor PDL1. ASS 1 levels were determined by Western Blotting and qPCR analyses (data not shown).

Cells were treated with increasing concentrations of ADI-PEG 20 or with $200 \mathrm{ng} / \mathrm{mL}$ IFN $\gamma$ for $24 \mathrm{~h}, 48 \mathrm{~h}$ or $72 \mathrm{~h}$. At each time point treated and non-treated cells were collected and surface stained with anti-PD-L1 mAb or isotype control antibody and co-stained with Live/ Dead fixable stain as described in Materials and Methods. To correct for non-specific binding we subtracted values obtained with isotype control antibody from those acquired after staining with anti-PD-L1 antibody.

A summary of the results is shown in Figure 1. In the majority of the tested cells lines $200 \mathrm{ng} / \mathrm{mL}$ IFN $\gamma$ had greater effect on PD-L1 upregulation than ADIPEG 20. Only in one cell line, AGS, treatment with high concentrations of ADI-PEG 20 upregulated PD-L1 more than observed for treatment with $200 \mathrm{ng} / \mathrm{mL}$ IFN $\gamma$. ADIPEG 20 and $200 \mathrm{ng} / \mathrm{mL}$ IFN $\gamma$ had similar effects in HT1080 cells further upregulating an already high PD-L1 level, and in PD-L1-low A2780 cells both agents induced only minor increase in PD-L1 (ADI-PEG 20 effect seen mainly at 72 h). In H1299 and Mia Paca-2 ADI-PEG 20 upregulated PD-L1 only slightly and in A375, SKOV3, HT29, and HCT116 ADI-PEG 20 increased surface PD-L1 several fold while $200 \mathrm{ng} / \mathrm{mL}$ IFN $\gamma$ increased it 20 fold or higher (based on median fluorescent intensity (MFI) values). ADI-PEG 20 had little to no effect on PD-L1 levels in SNU-398, SNU-16, Panc-1, K562 and SNU-1 cell lines. Treatment with $200 \mathrm{ng} / \mathrm{mL}$ IFN $\gamma$ greatly upregulated PD-L1 levels in SNU-1 and only modestly in SNU-398, SNU-16, Panc-1 and K562. As expected, in the ASS1-high (negative control) N87 cell line ADI-PEG 20 had no effect whereas $200 \mathrm{ng} / \mathrm{mL}$ IFN $\gamma$ prominently upregulated PD-L1 (data not shown).

PD-L1 encoding CD274 gene expression data by RT-qPCR generally paralleled PD-L1 cell surface level findings by flow cytometry; results are summarized in Figure 2 .

These data suggest PD-L1 upregulation was at least partially driven by gene expression.

\section{ADI-PEG 20 treatment does not affect resting PBMCs but when present during initial stimulation inhibits $\mathrm{T}$ cell activation past CD69 upregulation stage}

PBMCs were rested overnight and treated for $24 \mathrm{~h}$, $48 \mathrm{~h}$ or $72 \mathrm{~h}$ with $0-20 \mathrm{nM}$ ADI-PEG 20 in the presence or absence of anti-CD3/CD28 beads or Phytohaemagglutinin (PHA). To control for any potential effects of polyethylene glycol (PEG 20) and verify that the observed treatment outcomes with ADI-PEG 20 were indeed mediated by ADI activity we have evaluated the effect of $20 \mathrm{nM}$ of an inactive ADI mutant (with C397A substitution) PEGylated with $20 \mathrm{~K}$ PEG.

After incubation was complete cells were collected, stained for expression of surface markers and analyzed by immune cell phenotyping using flow cytometry. Six independent experiments were conducted with PBMCs from five different donors and the obtained results were consistent between experimental repeats. Representative data are shown in Figures 3-7.

ADI-PEG 20 treatment of PBMCs under resting conditions had no effect on the analyzed $\mathrm{T}$ cell subsets (Figures 3-7). 
When ADI-PEG 20 treatment was initiated simultaneously with anti-CD3/CD28 bead addition to PBMC cultures CD4+ and CD8+ $\mathrm{T}$ cells expressing early activation marker CD69+ persisted throughout the treatment while in the absence of ADI-PEG 20 or in the presence of mutant ADI-PEG 20 they have subsided (as expected) as shown in Figure 3A and 3B. This effect was more apparent at the high concentrations of ADI-PEG 20 which very quickly convert all media arginine into citrulline. The $0.8 \mathrm{nM}$ ADI-PEG 20 dose did not have a noticeable effect at the $24 \mathrm{~h}$ and $48 \mathrm{~h}$ time points and blocked CD69 downregulation at $72 \mathrm{~h}$, which reflects slower depletion of arginine at this concentration. Kinetics of arginine conversion into citrulline in the media by a range of ADI-PEG 20 concentrations are shown in Supplementary Figure 1.

PBMCs from three of the five donors had relatively high percentage of CD69+ $\mathrm{T}$ cells in the absence of activation. CD69 expression has decreased overtime as in freshly stimulated cultures and in this case ADI-PEG 20 did not affect the downregulation as shown in Figure $3 \mathrm{C}$.

Next, we analyzed percentage of T cells expressing another activation marker CD25 that is upregulated later than CD69 and remains high for a few days. When added simultaneously with anti-CD3/CD28 beads high (but not low) concentrations of ADI-PEG 20 reduced CD25+ T cells. When $5 \mathrm{nM}$ ADI-PEG 20 was added $24 \mathrm{~h}$ after the initiation of stimulation reduction in $\mathrm{CD} 25+\mathrm{T}$ cells was very modest and addition of 5 nM ADI-PEG $2048 \mathrm{~h}$ after activation had no effect on CD25 expression as shown in Figure 4.

Consistent with these findings IL-2 and IFN $\gamma$ secretion into media by anti-CD3/CD28 stimulated PBMCs was decreased when 5 nM ADI-PEG was present from the beginning of $\mathrm{T}$ cell activation, but not when added $24 \mathrm{~h}$ or $48 \mathrm{~h}$ after bead addition or when

A

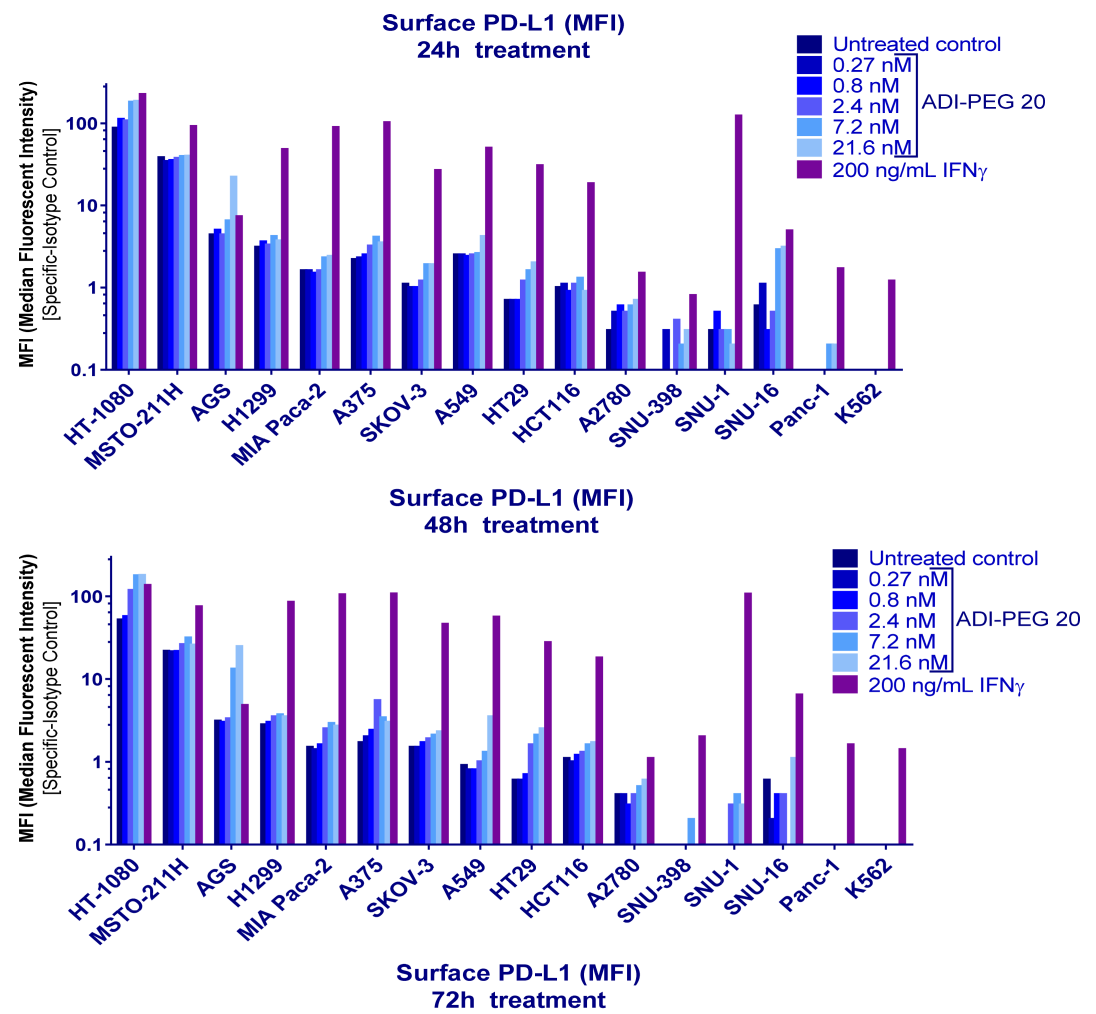

C $72 \mathrm{~h}$ treatment

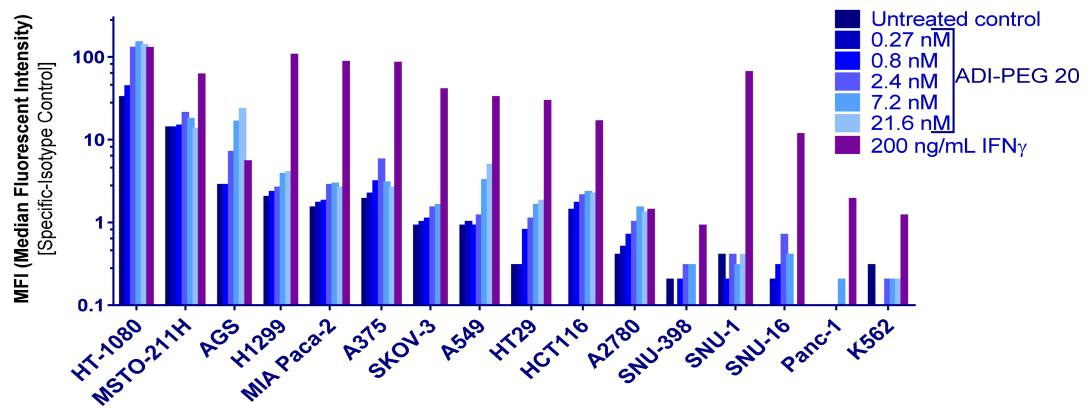

Figure 1: Effect of ADI-PEG 20 on PD-L1 cell surface levels in a cancer cell panel. Cancer cells were treated with serially diluted ADI-PEG 20 or IFN $\gamma$ control and their surface PD-L1 was assessed by flow cytometry at $24 \mathrm{~h}(\mathbf{A}), 48 \mathrm{~h} \mathrm{(B)}$ and $72 \mathrm{~h}(\mathbf{C})$ after the start of the treatment. 
used at lower concentrations (Figure 5). 5 nM ADI-PEG 20 rapidly depletes all arginine from the media while 0.5-1 nM concentrations convert arginine to citrulline more gradually (Supplementary Figure 1) leaving some (albeit low) arginine available during early activation events (at the beginning of the treatment).

Induction of PD-1 and CTLA-4 on CD4+ and CD8+ $\mathrm{T}$ cells starting at $48 \mathrm{~h}$ following stimulation was prevented by the treatment with high concentrations of ADI-PEG 20 (Figure 6A-6D). In the absence of stimulation or when added $48 \mathrm{~h}$ later than anti-CD3/CD28 beads ADI-PEG 20 had no effect on PD-1 and CTLA-4 expression (data not shown).

PD-L1 surface levels on $\mathrm{T}$ cells were greatly increased following anti-CD3/CD28 bead (or PHA) stimulation with surface PD-L1 detectable on almost all T cells by $48 \mathrm{~h}$. ADI-PEG 20 had little to no effect on PD-L1 levels at $24 \mathrm{~h}$ timepoint but when present at high concentrations ( 4 or $20 \mathrm{nM}$ ) it blocked further upregulation of PD-L1 in CD4+ and CD8+ T cells (Figure 6E-6F).

Non-functional mutant ADI-PEG 20 did not affect $\mathrm{T}$ cells under either resting or stimulating conditions.
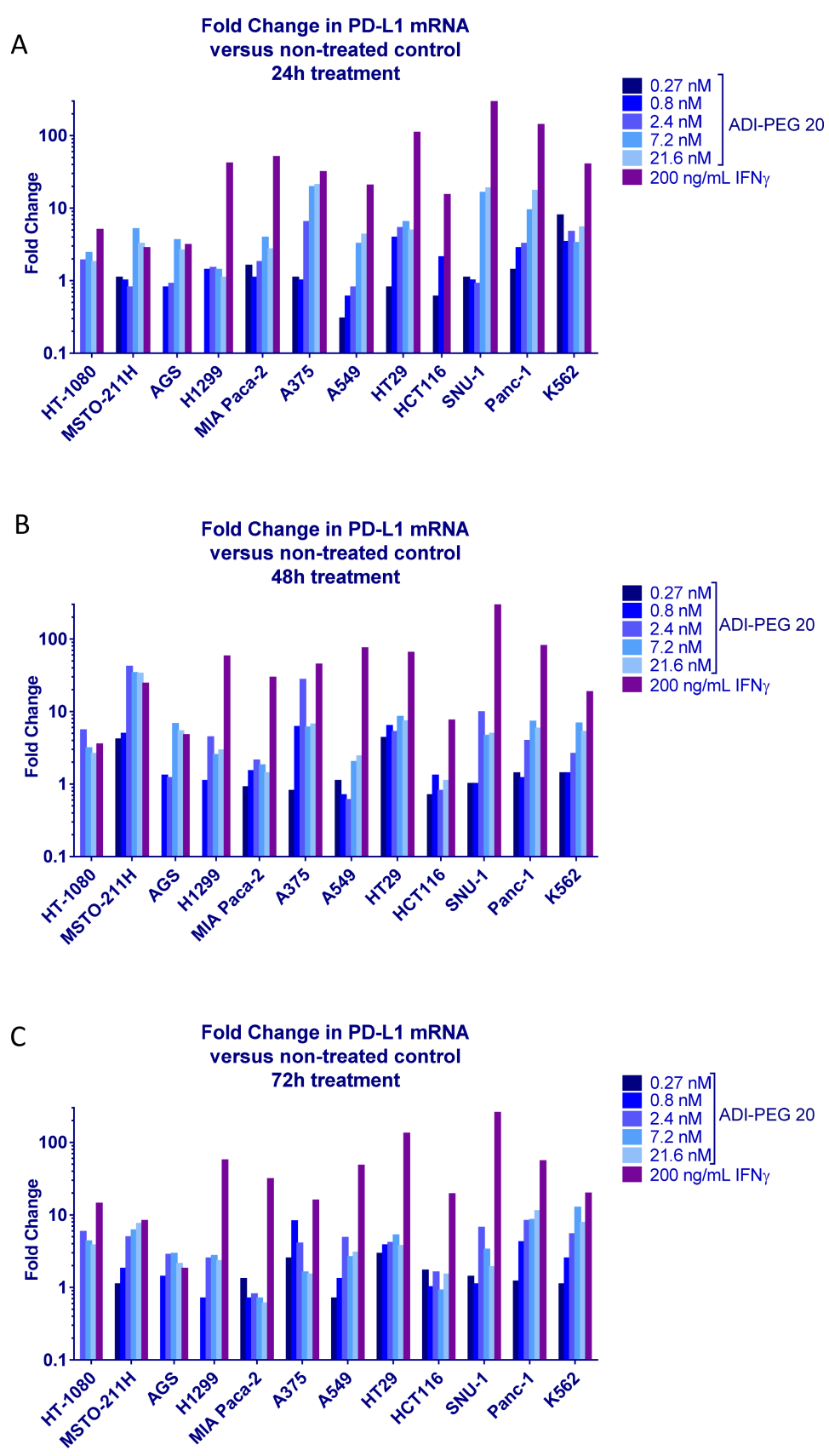

Figure 2: Effect of ADI-PEG 20 on PD-L1 expression in a cancer cell panel. Cancer cells were treated with serially diluted ADI-PEG 20 or IFN $\gamma$ control and PD-L1 mRNA levels were measured by RT-qPCR at $24 \mathrm{~h}(\mathbf{A}), 48 \mathrm{~h}(\mathbf{B})$ and $72 \mathrm{~h}(\mathbf{C})$ after the start of the treatment. $\beta$-actin mRNA was used for normalization. 


\section{ADI-PEG 20 inhibited induction of cells with regulatory $T$ cell markers}

Regulatory $\mathrm{T}$ cells are known to have CD3+CD4+CD25+FoxP3+CTLA-4+ phenotype. CD4+ $\mathrm{T}$ cells differentiation into $\mathrm{CD} 3+\mathrm{CD} 4+\mathrm{CD} 25+\mathrm{FoxP} 3+$ cells was inhibited by ADI-PEG 20 in a concentration dependent manner (Figure 7). ADI-PEG 20 at the $4 \mathrm{nM}$ and $20 \mathrm{nM}$ doses almost completely blocked induction of
$\mathrm{CD} 3+\mathrm{CD} 4+\mathrm{CD} 25+\mathrm{FoxP} 3+\mathrm{T}$ cells including those that co-expressed PD-L1 and CTLA-4 markers (Figure 7).

In preliminary experiments we have also included CD127 marker for identification of regulatory $\mathrm{T}$ cells and the results were similar whether or not gating on CD127cells was included (almost all CD3+CD4+CD25+FoxP3+ were CD127-, data not shown).

Similar to the T cell activation data (CD69 levels) the $0.8 \mathrm{nM}$ ADI-PEG 20 dose was not effective after 24

A

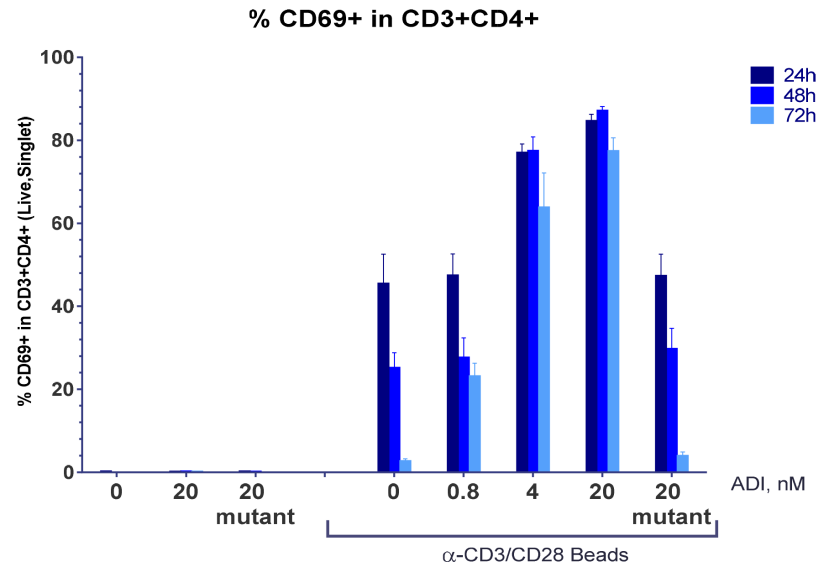

B

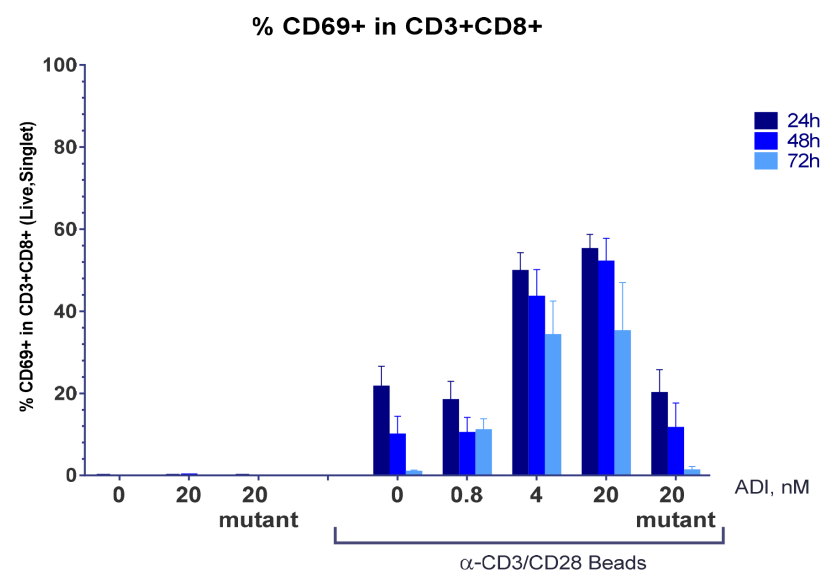

C

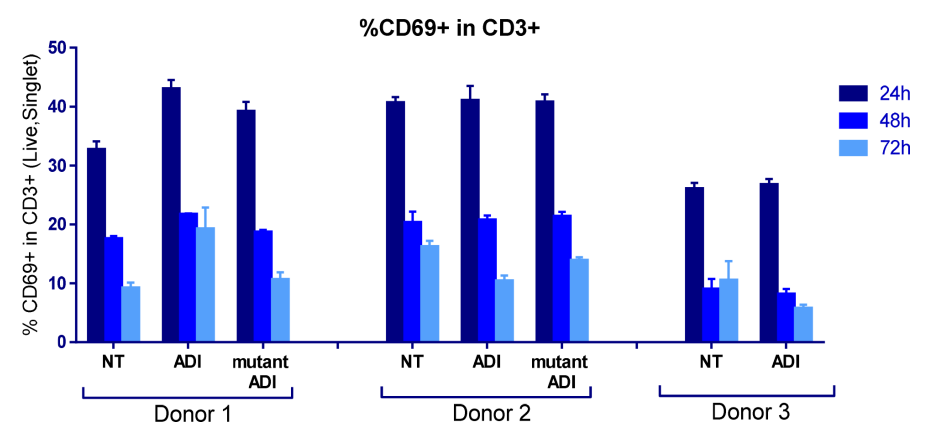

Figure 3: ADI-PEG 20 treatment during PBMC stimulation and not under resting conditions lead to a sustained increase in CD69+ $\mathbf{T}$ cells. PBMCs were stimulated with anti-CD3/CD28 Dynabeads in the presence or absence of ADI-PEG 20 or mutant ADI-PEG 20. Percentages of CD69+ cells among CD4 $+\mathrm{T}$ cells $(\mathbf{A})$ and CD8 $+\mathrm{T}$ cells $(\mathbf{B})$ were determined by flow cytometry at $24 \mathrm{~h}, 48 \mathrm{~h} \& 72 \mathrm{~h}$. PBMCs containing CD69+ T cells in the absence of stimulation were not affected by $20 \mathrm{nM}$ ADI-PEG 20 or mutant ADI-PEG 20 (C). NT - non-treated. 


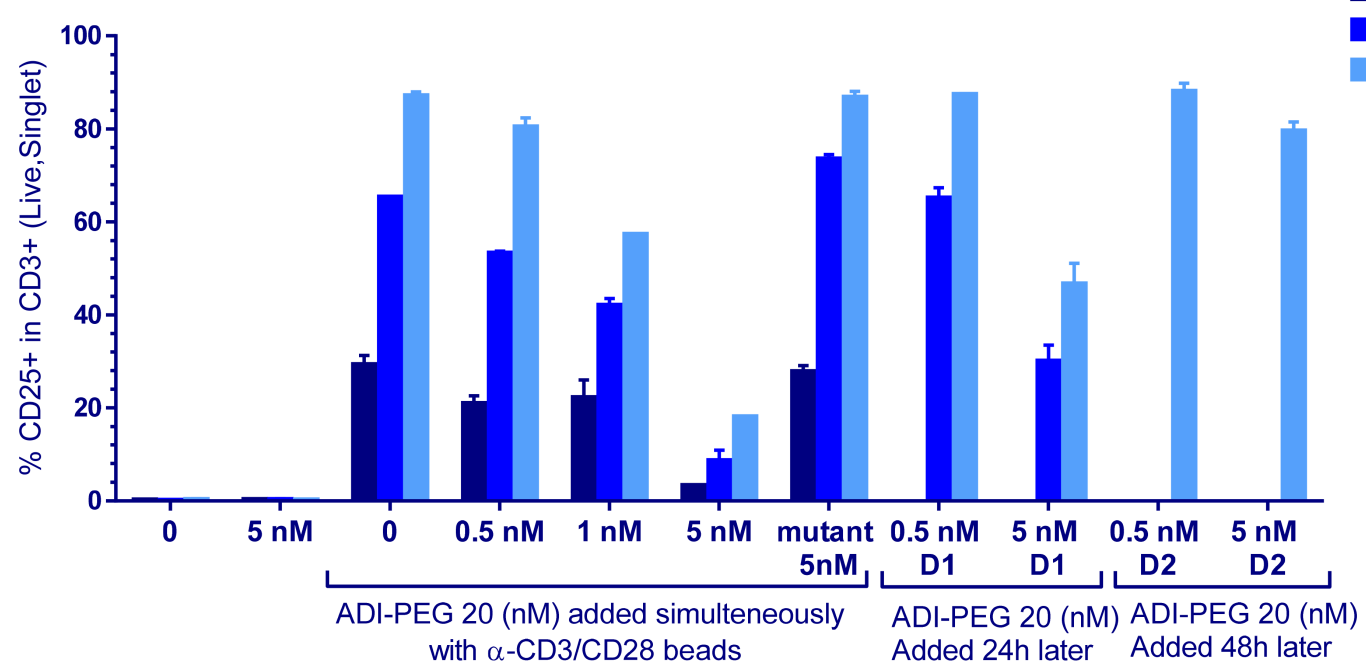

$\alpha-C D 3 / C D 28$ beads

Figure 4: CD25+ $\mathrm{T}$ cell induction was affected by high (and not low) concentrations of ADI-PEG 20 when added during PBMC stimulation and not under resting conditions or when added $48 \mathrm{~h}$ after the addition of anti-CD3/CD28 Dynabeads.

A

IL-2 Secreted into the Media by $\alpha-C D 3 / C D 28$ stimulated PBMCs

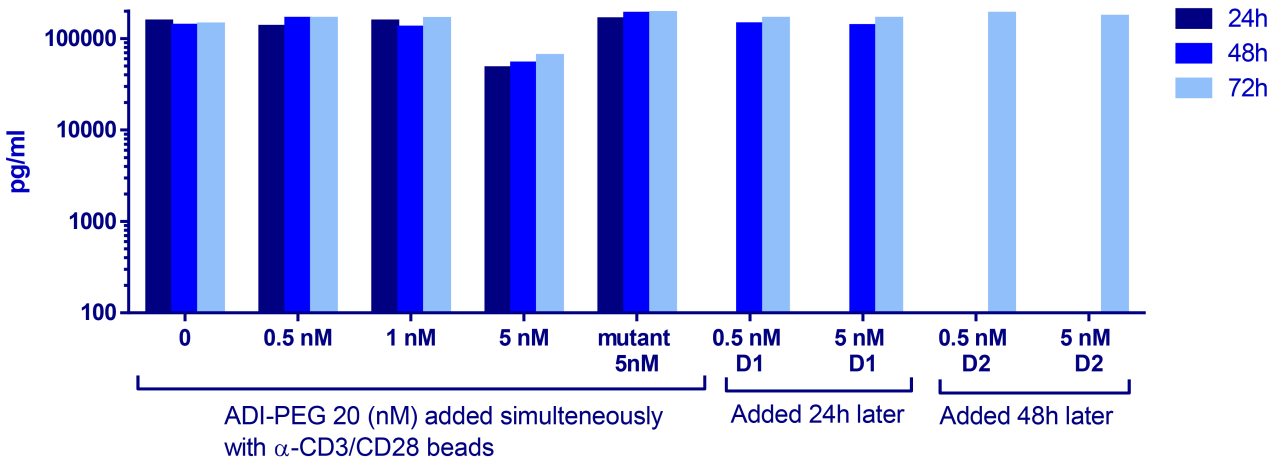

B IFN $\gamma$ Secreted into the Media by $\alpha-C D 3 / C D 28$ stimulated PBMCs

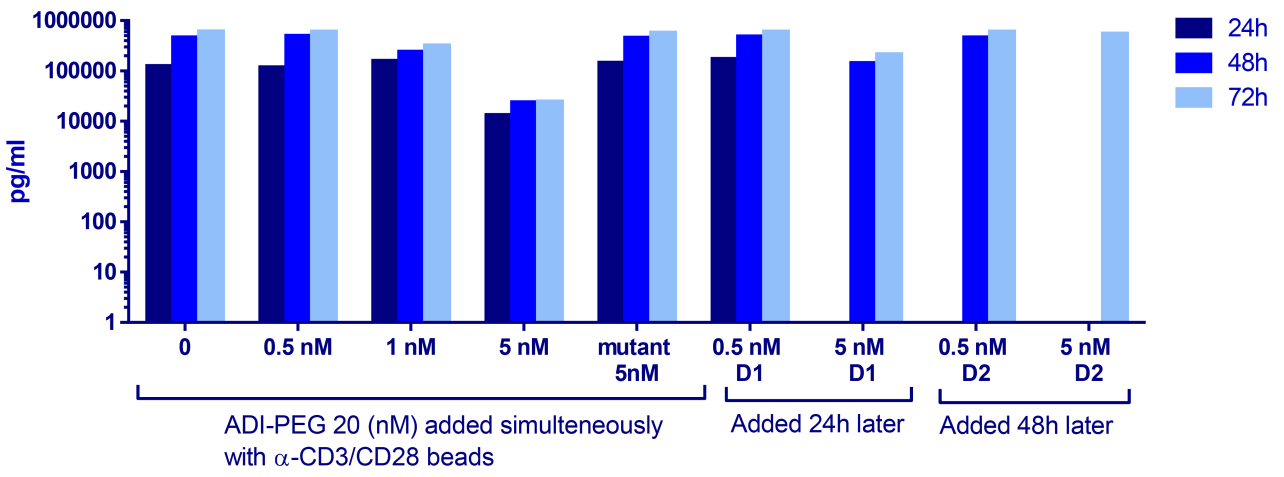

Figure 5: IL-2 (A) and IFN $\gamma(\mathbf{B})$ secretion by PBMCs after stimulation with anti-CD3/CD28 Dynabeads in the presence or absence of ADI-PEG 20 or mutant ADI-PEG 20. ADI-PEG 20 was added simultaneously with the beads or $24 \mathrm{~h}$ or $48 \mathrm{~h}$ later. IL2 and IFN $\gamma$ in the media were measured by ELISA at $24 \mathrm{~h}, 48 \mathrm{~h}$ and $72 \mathrm{~h}$ after initiation of the stimulation. 
$\mathrm{h}$ or $48 \mathrm{~h}$ of treatment but reduced cells with regulatory $\mathrm{T}$ cell markers at the $72 \mathrm{~h}$ time point.

PBMC viability was not reduced by ADI-PEG 20 as shown in Supplementary Figure 2.

PBMC proliferation was not affected under nonstimulated conditions while in the presence of antiCD3/CD28 beads ADI-PEG 20 inhibited proliferation when present at $1-5 \mathrm{nM}$ concentration but not at $0.5 \mathrm{nM}$ (Supplementary Figure 3).

\section{ADI-PEG 20 induced T cell infiltration in B16 melanoma model}

C57BL/6 mice were implanted with B16-F10 melanoma cells and treated, as described in Materials and Methods, by intramuscular injections with either PBS (control group) or $12 \mathrm{mg} / \mathrm{kg}$ of ADI-PEG 20 (experimental group); treatments were administered on day 1 and day 7 after tumor implantation. On day 14 after tumor implantation animals were euthanized and their tumors were removed and paraffin-embedded for IHC analysis. Tumor sections were stained with anti-CD3 $\mathrm{mAb}$ to determine whether ADI-PEG 20 treatment promoted T cell infiltration into the tumors. As expected, the PBS-treated animals had very few $\mathrm{T}$ cells present in their tumors. Conversely, five out of six ADI-PEG 20 treated animals had a large presence of T cells in their tumors which was statistically significant $(p<0.0001)$ when comparing to the average number of T cells present in the tumors of control animals using one-way Anova with Dunnett's test. Average number of TILS per tumor section is shown in Figure 8A and representative images in Figure $8 \mathrm{~B}$. Both CD4+ and CD8+ T cells were present among the infiltrating $\mathrm{T}$ cells (data not shown).
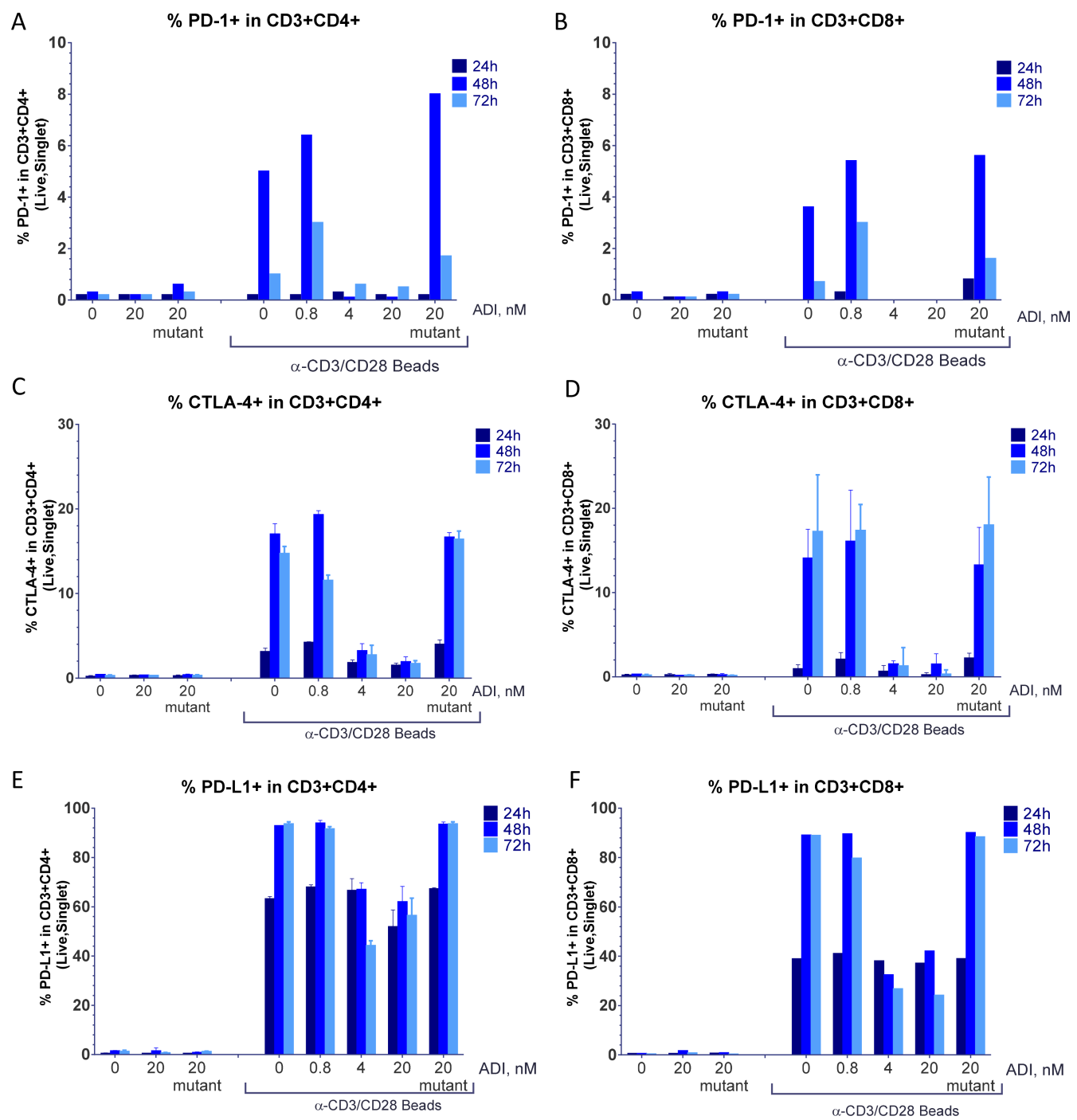

Figure 6: ADI-PEG 20 blocks anti-CD3/CD28 induced upregulation of PD-1, CTLA-4 and PD-L1 on T cells. PBMCs were stimulated with anti-CD3/CD28 Dynabeads in the presence or absence of ADI-PEG 20 or mutant ADI-PEG 20. Percentages of PD-1+ $(\mathbf{A}-\mathbf{B})$, CTLA-4+ $(\mathbf{C}-\mathbf{D})$ and PD-L1+ $(\mathbf{E}-\mathbf{F})$ cells in CD4+ T cells $(\mathrm{A}, \mathrm{C}, \mathrm{E})$ and CD8+ T cells $(\mathrm{B}, \mathrm{D}, \mathrm{F})$ were determined by flow cytometry at $24 \mathrm{~h}, 48 \mathrm{~h} \& 72 \mathrm{~h}$. 


\section{ADI-PEG 20 inhibits tumor growth in syngeneic models}

Next, we investigated whether ADI-PEG 20 can be effective in reducing tumor growth in vivo in immunocompetent models. In addition to studying effect of ADI-PEG 20 as a single agent we assessed if it would be beneficial to combine it with PD-1/PD-L1 neutralizing antibodies. B16-F10 melanoma and CT26 colon carcinoma models were used in these studies (conducted at a CRO). Both B16-F10 and CT26 are arginine auxotrophic cancers as ADI-PEG 20 inhibits their growth in vitro (Supplementary Figure 4A and 4B). In vivo studies were performed as described in Materials and Methods and results are shown in Figures 9 and 10.

In both B16-F10 and CT26 models ADI-PEG 20 slowed tumor growth and was well-tolerated. The B16-F10 model, as set up in the CRO where we have conducted the studies, is somewhat immunogenic and therefore anti-mouse PD-1 mAb was moderately effective in reducing tumor growth $(p<0.01)$. ADI-PEG 20 was less effective than anti-PD-1 mAb (not statistically significant) and only slightly reduced tumor growth (Figure 9). The combination of ADI-PEG 20 and anti-PD-1 mAb was more effective than either agent alone (not statistically significant).

In CT26 model ADI-PEG 20 had greater effect on tumor growth inhibition compared to anti-mPD-L1 antibody and their combination was better than either agent alone (not statistically significant). Survival analysis (mice were euthanized once their tumors reached $\sim 3000$ $\mathrm{mm}^{3}$ ) showed similar trends as more mice survived when treated with the combination of ADI-PEG 20 and antiPD-L1 mAb (Figure 10C).

\section{DISCUSSION}

ADI-PEG 20 can inhibit cell proliferation in vitro and tumor growth in vivo and is being investigated in clinical trials for ASS1-deficient tumors. To date ADI-PEG 20 has been demonstrated to be well-tolerated and shown promise in clinical studies [1-7].

To better understand potential impact of ADIPEG 20 on immune microenvironment we have studied its effect on expression of immunosuppressive PD-L1 on tumor cells. PD-L1 levels can be affected by various stimuli, for instance, signaling through the MEK/ERK and the PI3K/AKT pathways has been shown to increase PD-
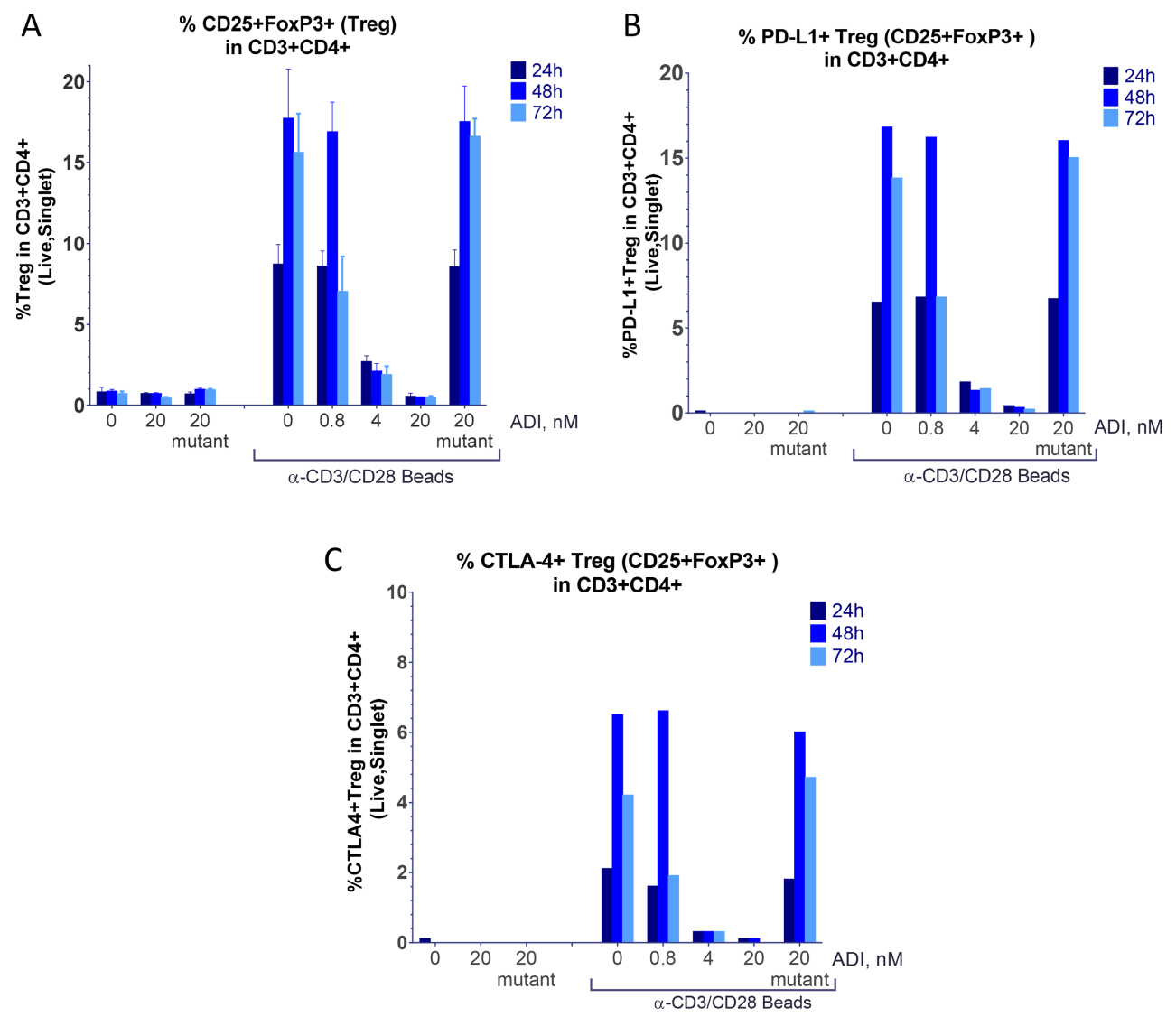

Figure 7: ADI-PEG 20 inhibits accumulation or T cells with Treg markers. PBMCs were stimulated with anti-CD3/CD28 Dynabeads in the presence or absence of ADI-PEG 20 or mutant ADI-PEG 20. Percentages of Treg cells among CD4+ T cells were determined by flow cytometry at $24 \mathrm{~h}, 48 \mathrm{~h} \& 72 \mathrm{~h}$. Treg cells were determined by CD3+CD4+CD25+FoxP3+(A), CD3+CD4+CD25+FoxP3+PD-L1+ (B) or CD3+CD4+CD25+FoxP3+CTLA-4+ (C) markers. 
L1 expression [30, 31] and Tsai et al. [32] have reported RAS/PI3K/ERK pathway activation by ADI-PEG 20 in some cancer cell lines.

When studying effects of ADI-PEG 20 on PD-L1 levels in a panel of cancer cell lines we compared its effects to those of INFg. Immune attack via IFN $\gamma$ release leads to upregulation of PD-L1 creating an "immune shield" to protect normal mucosa from autoimmune attack in the setting of chronic inflammation or infection. Tumor cells have co-opted the PD-1/PD-L1 regulatory mechanism to avoid immunologic surveillance thereby facilitating cancer growth. INFg has been shown to induce PD-L1 in a number of cancer cells lines [33-36]. ADIPEG 20 elicited a concentration-dependent increase in
PD-L1 mRNA expression (Figure 2) which translated into increased PD-L1 surface protein expression (Figure 1). In the majority of the tested cell lines the magnitude of PD-L1 upregulation induced by ADI-PEG 20 was much smaller than that induced by IFN $\gamma$. The mechanism of PD-L1 upregulation that we have observed in certain cancer cell lines is not known. ADI-PEG 20 induced slight upregulation of PD-L1 it A375 cells where according to Tsai et al. [32] ADI-PEG 20 cannot activate RAS/PE3K/ ERK pathway.

To learn how ADI-PEG 20 may affect $T$ cells we treated healthy human PBMCs under resting conditions or when stimulated with anti-CD3/CD28 beads. PBMCs maintained high viability after ADI-PEG 20 treatment

\section{A}

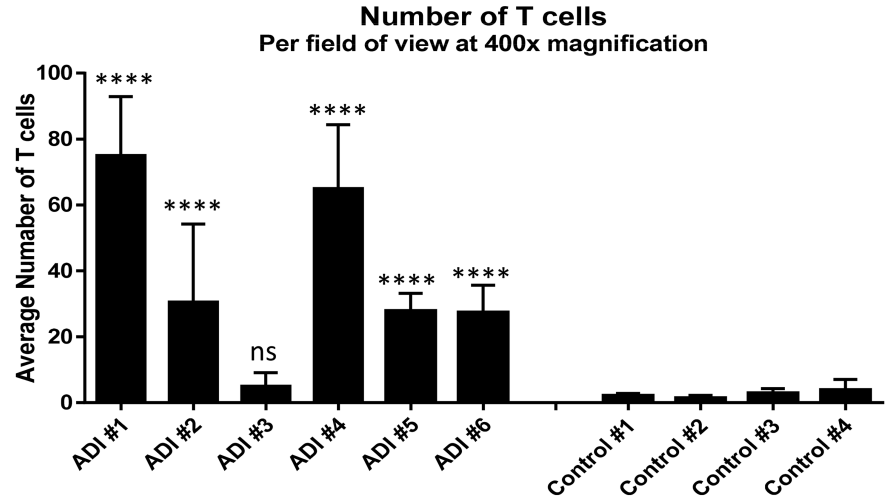

B

Treatment Group, Animal\#
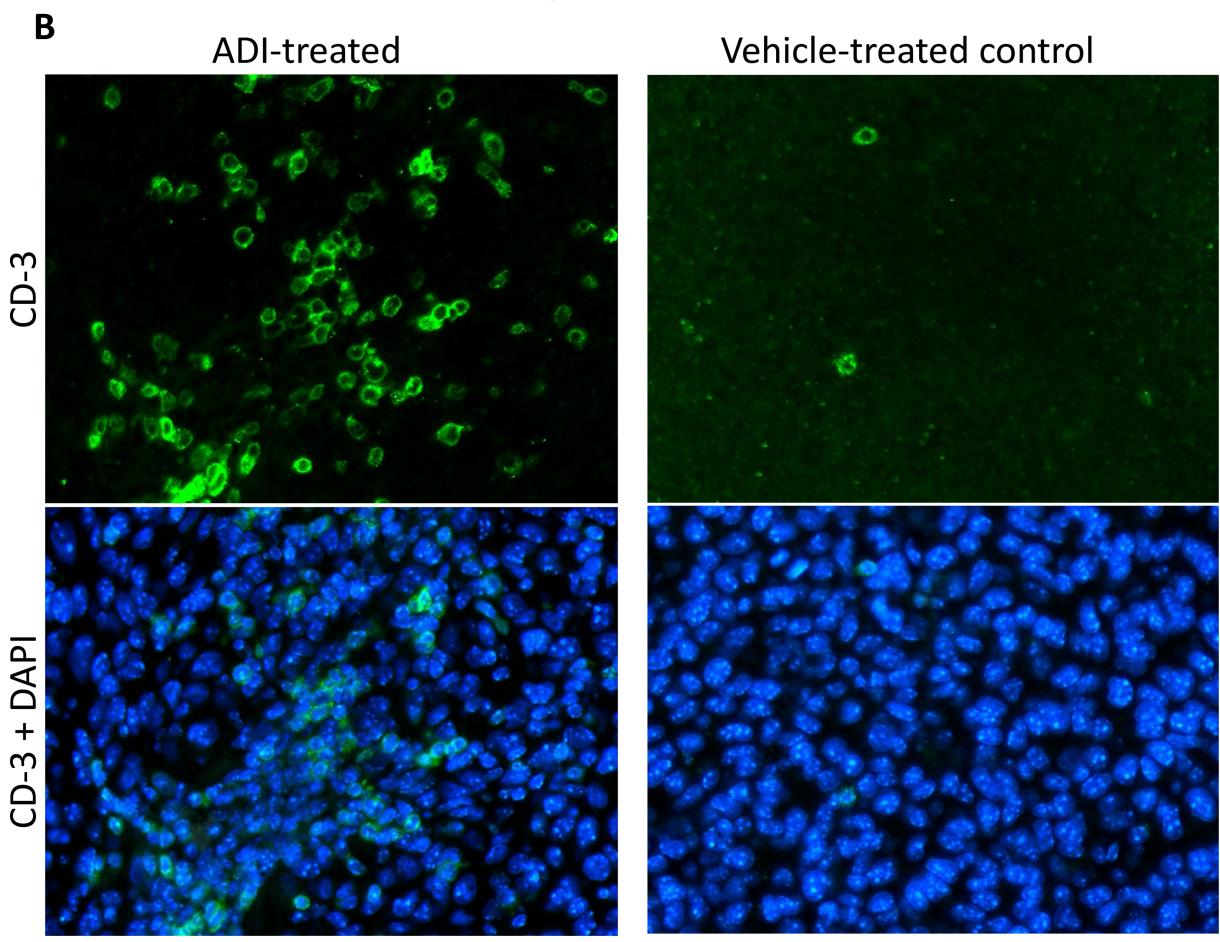

Figure 8: ADI-PEG 20 induces T cell infiltration into B16-F10 tumors. B16-F10 cells were implanted into C57BL/6 mice and the mice were treated IM with $12 \mathrm{mg} / \mathrm{kg}$ of ADI-PEG 20 or vehicle (PBS) control on $\mathrm{d} 1$ and $\mathrm{d} 7 \mathrm{post}$ tumor implantation. On day 14 tumors were removed and sectioned. Sections were stained by IHC with anti-CD3 mAb and counterstained with DAPI. Number of T cells per field at $400 \times$ was counted in four sections of each tumor and averaged (A), representative images taken at 400× magnification (B). One-way Anova was used for statistical analysis, ns - non significant, ${ }^{* * * *} p<0.0001$. 
(Supplementary Figure 2), which is consistent with previous findings that arginine starvation does not affect $\mathrm{T}$ cell viability $[17,37]$.

When used at high concentrations that quickly convert all available media arginine into citrulline ADIPEG 20 inhibited $\mathrm{T}$ cell activation progression past the initial stage, PBMC proliferation. Early activation marker CD69+ was upregulated on CD4+ and CD8+ T cells in the presence of ADI-PEG 20 and remained at high levels throughout our analyses (up to $72 \mathrm{~h}$ post stimulation). On the other hand CD25+ T cells and IL-2 and IFN $\gamma$ secretion into the media were decreased by $5 \mathrm{nM}$ ADI-PEG 20 when added at the beginning of PBMC stimulation. These results are consistent with previously reported findings by Munder et al. [37] who observed increased CD69 and decreased CD25 expression on T cells stimulated in arginine-free versus arginine-containing media. When 5 nM ADI-PEG 20 was added $24 \mathrm{~h}$ after stimulation was initiated it did not reduce IL-2 secretion and only mildly inhibited CD25 upregulation; delaying ADI-PEG 20 treatment by $48 \mathrm{~h}$ after stimulation or using it at lower concentrations (less than $1 \mathrm{nM}$ ) eliminated its effects on CD25 upregulation and cytokine secretion. Thus, complete absence of arginine during T cell stimulation can suppress their activation while presence of low arginine or its removal later in the process is not inhibitory.

While $\mathrm{T}$ cells can utilize citrulline to synthetize their own arginine this regeneration pathway may not be sufficient to satisfy high metabolic needs for arginine during priming. Geiger and colleagues recently showed that there is an abrupt decrease in intracellular arginine between 24 and 48 hours after T cell activation [38].
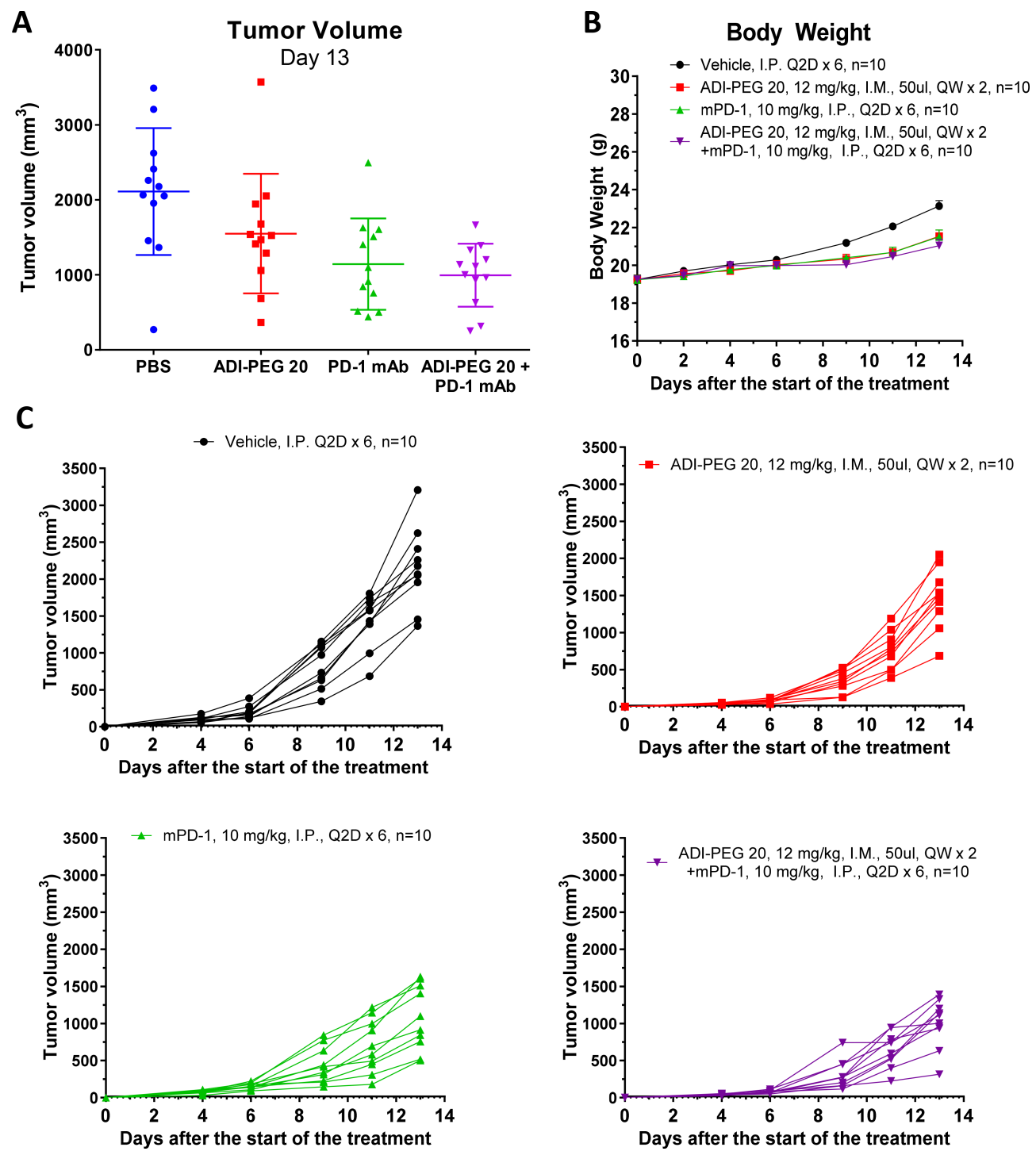

Figure 9: ADI-PEG 20 reduces B16-F10 tumor growth as a single agent and in combination with anti-mPD-1 mAb. B16-F10 cells were implanted into C57BL/6J mice and the next day the mice were treated with $12 \mathrm{mg} / \mathrm{kg}$ of ADI-PEG 20 QWx2 IM, $10 \mathrm{mg} /$ $\mathrm{kg}$ anti-mPD-1 Q2D IP, $12 \mathrm{mg} / \mathrm{kg}$ of ADI-PEG 20 QWx2 IM and $10 \mathrm{mg} / \mathrm{kg}$ anti-mPD-1 Q2D IP or vehicle (PBS) control. Tumor volume (A and $\mathbf{C}$ ) and body weight (B) were monitored for two weeks. 
Upregulation of $\mathrm{T}$ cell exhaustion markers CTLA-4, PD-1 and PD-L1 was also inhibited by ADI-PEG 20 when present during PBMC stimulation.

CD4+ $\mathrm{T}$ cell differentiation into cells characterized by markers found on regulatory $\mathrm{T}$ cells $(\mathrm{CD} 3+\mathrm{CD} 4+\mathrm{CD} 25+\mathrm{FoxP} 3+\mathrm{CTLA}-4+)$ was particularly sensitive to ADI-PEG 20 treatment as even less than 1 $\mathrm{nM}$ concentrations suppressed accumulation of these cells (Figure 7). It appears that various T cell subsets have differential sensitivity to ADI-PEG 20 when it is present at the start of stimulation. As mentioned earlier ADI-PEG 20 does not appear to affect $\mathrm{T}$ cells when added before or after initial stimulation.

Thus, while complete depletion of arginine in lymph nodes during $\mathrm{T}$ cell priming would have negative effect on their activation low arginine concentrations are likely to be tolerated (especially in the presence of high citrulline) and may inhibit regulatory $\mathrm{T}$ cell accumulation. In tissues

\section{A}

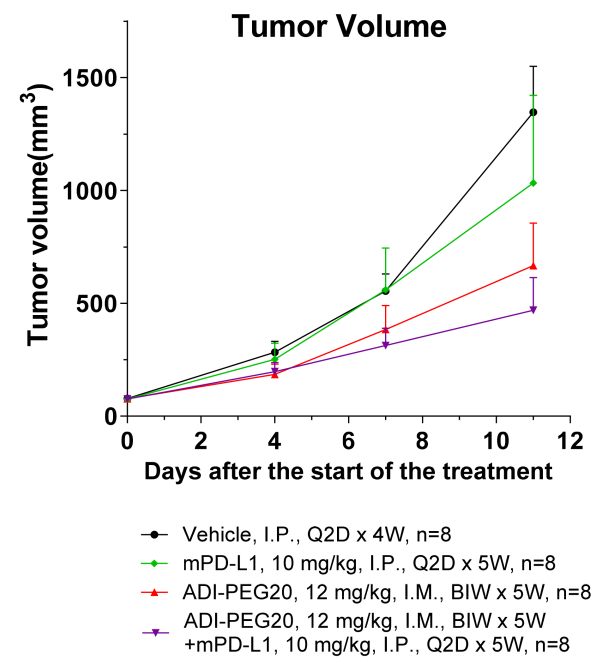

ADI-PEG 20 is unlikely to impact already activated T cells.

Further studies are needed to better understand consequences of ADI-PEG 20 treatment on tumor microenvironment in vivo. Apart from potential effects on T cells ADI-PEG 20 may affect myeloid cells as it competes for substrate with L-arginase and iNOS enzymes present in MDSCs and macrophages. L-arginine and L-citrulline have been shown to have differential effects on macrophages. When arginine is depleted in the media M1 macrophages produce NO from citrulline (transported from the media) using the arginine regeneration pathway. NO production from citrulline was not blocked by arginase as it was when L-arginine was present in the media [39].

To analyze how ADI-PEG 20 affects tumors in immunocompetent environment we studied its effect in syngeneic models. We conducted initial studies inhouse using poorly immunogenic B16-F10 mouse

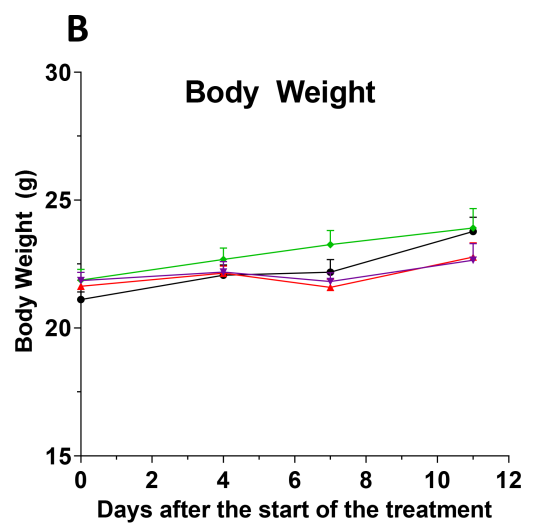

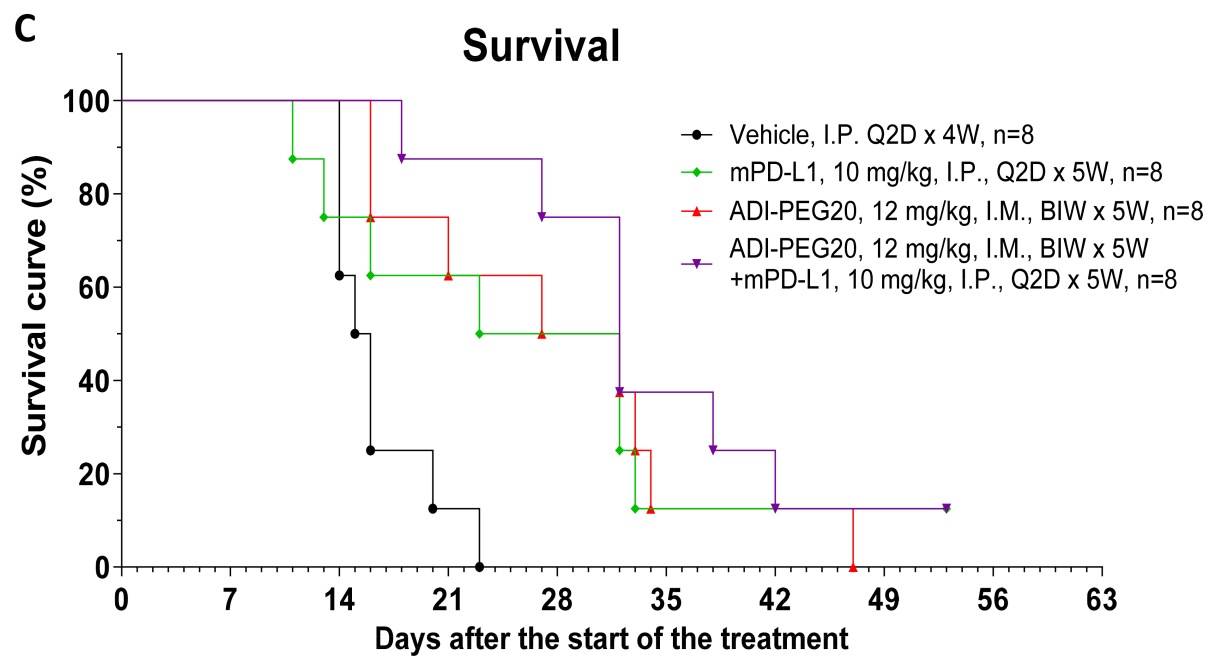

Figure 10: ADI-PEG 20 reduces CT26 tumor growth and prolongs survival as a single agent and in combination with anti-mPD-L1 mAb. CT26 cells were implanted into Balb/c mice and the next day the mice were treated with $12 \mathrm{mg} / \mathrm{kg}$ of ADI-PEG 20 BIWx5W IM, $10 \mathrm{mg} / \mathrm{kg}$ anti-mPD-L1 Q2D x 5W IP, $12 \mathrm{mg} / \mathrm{kg}$ of ADI-PEG 20 IM BIWx5W and $10 \mathrm{mg} / \mathrm{kg}$ anti-mPD-L1 IP Q2D x 5W or vehicle (PBS) control. Tumor Volume (A), body weight (B) and survival (C) were assessed over time. 
melanoma model. B16-F10 cells have high ASS1 levels (Supplementary Figure 4C) however, ADI-PEG 20 inhibited their growth in vitro possibly due to a mutation in ASS1 or deficiency/mutation in another enzyme (e.g. argininosuccinate lyase) involved in the conversion of citrulline to arginine. Alternatively, B16-F10 cells may not be able to produce arginine from citrulline fast enough or deplete the nitrogen source needed to convert citrulline back to arginine.

IHC analysis of the B16-F10 tumor sections revealed that treatment with ADI-PEG 20 led to a marked increase in tumor infiltrating $\mathrm{T}$ cells. In contrast to the low level of tumor $\mathrm{T}$ cell infiltrate found in the non-treated mice, five out of six ADI-PEG 20 treated animals had a large number of $\mathrm{T}$ cells in their tumors (Figure 8), both CD4+ and $\mathrm{CD} 8+$ (data not shown). This suggests that ADIPEG 20 may improve tumor immunogenicity. However, we don't know what caused this infiltration (possibly instigated by inflammation) or its exact composition and functional state.

We have conducted tumor growth inhibition studies at a CRO where B16-F10 model is moderately immunogenic and responds to the treatment with anti-mPD-1 mAb. ADI-PEG 20 was somewhat less efficacious than anti-PD-1 $\mathrm{mAb}$ in this model (not statistically significant). Importantly, combination of ADI-PEG 20 and anti-mPD-1 mAb appeared to be additive (Figure 9).

ADI-PEG 20 also reduced tumor growth and prolonged survival in another moderately immunogenic model, colon carcinoma CT26. This is also arginine auxotrophic cancer whose growth is inhibited by ADI-PEG 20 in vitro due to very low ASS1 levels (Supplementary Figure $3 \mathrm{~B}$ and 3C). Combining ADI-PEG 20 with anti-mPD-L1 mAb in vivo resulted in superior tumor growth control and survival compared with either agent alone (not statistically significant) as shown in Figure 10. It is encouraging that ADI-PEG 20 has activity in immunocompetent models and seems to be additive with immune checkpoint blockers anti-PD-1 and anti-PD-L1 mAbs.

\section{MATERIALS AND METHODS}

\section{Reagents}

ADI-PEG 20 is a recombinant protein cloned from Mycoplasma hominis and subsequently produced in Escherichia coli. The recombinant protein is PEGylated with 20,000 MW PEG [40-42]. C397A substitution was used to generate the inactive ADI-PEG 20 mutant.

Frozen healthy donor PBMCs were purchased from AllCells. Cancer cell lines AGS, A2780, A375, HCT116, HT29, HT-1080, K562, SNU-1, SN-16, SNU-5, SNU-398, N87, A549, MSTO, SKOV-3, Mia-Paca-2, Panc-1, H1299 were purchased from ATCC.
TaqMan $^{\circledR}$ Gene Expression Cells-to-CT ${ }^{\mathrm{TM}}$ Kit, IFN $\gamma$, Live/Dead fixable stains (Green and Near-IR), PHA, AIM-V medium, Glutamax, CD3/CD28 Dynabeads, DynaMag-5, SimplyBlue ${ }^{\mathrm{TM}}$ SafeStain, BCA assay kit, mouse anti-GAPDH monoclonal antibody HRP conjugate and SuperSignal West Femto maximum sensitivity substrate were obtained from ThermoFisher Scientific.

The following flow cytometry reagents were acquired from BD Bioscience - SB(BSA) buffer, human Fc block, human FoxP3 buffer set, AbC total antibody compensation bead kit, ArC amine reactive bead kit and antibodies specific to CD274-APC clone MIH1, CD279-PE clone MIH4, CD152-PE clone BNI3, CD3PE-Cy7 clone SK7, CD8-FITC clone SK1, CD4-PerCPCy5.5 clone SK3, CD69-APC clone FN50, CD25-APC clone M-A251, CD127-PE clone HIL-7-M21, FoxP3Alexa-488. CD274-PE clone 29E.2A3 and CFSE were purchased from BioLegend.

RIPA buffer and protease inhibitors were purchased from Sigma.

Goat anti-mouse IgG-HRP was from Santa Cruz Biotech.

For IHC studies the following antibodies were used: anti-CD3 rabbit $\mathrm{mAb}$ [SP7] from Abcam, antiCD4 polyclonal Guinea pig antiserum and anti-CD8a polyclonal rabbit antibodies were from SYSY, whole IgG donkey anti-rabbit and anti-guinea pig were from Jackson ImmunoResearch.

\section{PMBC treatment}

PBMCs from five different donors were tested in six repeat experiments. PBMCs were thawed, washed and rested overnight $(18 \mathrm{~h})$. The next day cells were collected, resuspended in AIM-V medium supplemented with Glutamax and counted. Cell concentration was adjusted to $2 \times 10^{\wedge} 6$ cells per $\mathrm{mL}$ and $2 \mathrm{~mL}$ of cells were added per well of a 6-well plate. PBMCs were treated with $0,0.8,4$ or $20 \mathrm{nM}$ of ADI-PEG 20 in the presence or absence of CD3/CD28 Dynabeads or PHA. CD3/CD28 Dynabeads were prepared according to manufacturer's instructions. Cells were analyzed after $24 \mathrm{~h}, 48 \mathrm{~h}$ and $72 \mathrm{~h}$ of treatment.

Citrulline and arginine levels in the media were measured by LC/MS/MS.

IL-2 was measured by human IL-2 ELISA kit and IFN $\gamma$ was measured by human IFN $\gamma$ ELISA MAX Deluxe kit (BioLegend).

\section{Cancer cell lines treatment}

Cancer cell lines were cultured according to manufacturer's instructions. Cells were treated with increasing concentrations of ADI-PEG 20 and analyzed after $24 \mathrm{~h}, 48 \mathrm{~h}$ or $72 \mathrm{~h}$ incubation.

The effect of ADI-PEG 20 on cell viability and caspase $3 / 7$ induction was analyzed by ApoTox-Glo triplex assay (Promega). 


\section{Flow cytometry analysis}

\section{PBMC}

Prior to flow cytometry analysis Dynabeads were removed from samples. Cells were blocked in human Fc block, stained with Live/Dead fixable Near-IR stain followed by appropriate antibody solution mixes. For effector $\mathrm{T}$ cell (Teff) analyses antibody mix contained: CD3-PE-Cy7, CD8-FITC, CD4-PerCP-Cy5.5, CD69APC and either CD274-PE, CD279-PE or CD152-PE. For analysis of regulatory $\mathrm{T}$ cells (Treg) antibody mix included CD3-PE-Cy7, CD4-PerCP-Cy5.5, CD25-APC and either CD127-PE, CD274-PE, CD279-PE or CD152-PE. After surface staining samples were washed, those stained with Teff antibody mix were immediately analyzed by flow cytometry, while samples stained with Treg antibody mix were permeabilized with human FoxP3 buffer set and intracellularly stained with FoxP3-FITC antibody. Fifty thousand events were acquired for each sample on a Guava EasyCyte 8HT (Millipore). Data acquisition and analysis were performed with InCyte software (Millipore). AbC total antibody compensation bead kit and ArC amine reactive bead kit were used to create single stained fluorophore controls and perform spectral overlap compensation on the cytometer.

Gating strategy: Singlet gate was determined by FSC-H versus FSC-A plot. Fluorescent minus one (FMO) controls were used to set up other analyses gates. Singlet cells were gated on live cells based on Live/Dead fixable Near-IR stain and singlet and live cells were further analyzed for the presence of CD3 T cell marker. Within CD3+ live and singlet cells CD4+ and CD8+ gates were set up, then each of these populations were analyzed for the presence of other markers - CD69, CD274, CD279, CD152. For Treg analysis singlet and live CD3+CD4+ cells were analyzed for the presence of CD25, FoxP3, CD127, CD274, CD279 and CD152 markers.

For proliferation studies PMBCs were labeled with CFSE prior to the treatment. Briefly, CFSE was diluted to $5 \mu \mathrm{M}$ in PBS, cells were resuspended in CFSE solution and incubated for 20 minutes at $37^{\circ} \mathrm{C}$. The dye was quenched with 5 volumes of culture media with $10 \%$ FBS. Cells were pelleted and resuspended in pre-warmed culture medium.

\section{PD-L1 surface levels in cancer cell lines}

Cell were collected and washed in cold SB(BSA) buffer. Then cells were resuspended in $80 \mu \mathrm{L}$ SB(BSA) buffer and incubated at room temperature for at least 10 min. Each sample was split in two $(40 \mu \mathrm{L}$ each) for specific staining with anti-PD-L1 mAb and to assess non-specific binding with isotype control antibody. Live/Dead fixable green stain was prepared according to manufacturer's instructions and the solubilized stain was diluted 1:10 in SB(BSA) buffer. Then $0.5 \mu$ of the diluted Live/Dead fixable green stain and either $2.5 \mu \mathrm{L}$ anti-CD274-APC mAb $+7.5 \mu \mathrm{L} \mathrm{SB}$ (BSA) or $10 \mu \mathrm{L}$ isotype control-APC $\mathrm{mAb}$ was added to each sample. Samples were incubated on ice protected from light for 35 min, washed twice in SB(BSA) buffer and resuspended in $150 \mu \mathrm{L}$ of $\mathrm{SB}(\mathrm{BSA})$ buffer. Non-stained and single stained controls were used to adjust instrument settings. Ten thousand events were acquired for each sample on a Guava EasyCyte 8HT (Millipore). Data acquisition and analysis were performed with InCyte software (Millipore). Cells were gated on singlets (determined by FSC-H versus FSC-A) and live cells within the singlet gate were analyzed for PD-L1 levels. Percent PD-L1 positive and mean and median fluorescent intensity were determined by subtracting background signal determined with isotype control antibody from specific signal obtained with antiPD-L1 antibody.

\section{RT-qPCR}

RT-qPCR was conducted with TaqMan $^{\circledR}$ Gene Expression Cells-to- $\mathrm{CT}^{\mathrm{TM}}$ Kit according manufacturer instructions. The qPCR step was performed with primerprobe mixes purchased from IDT multiplexing an assay for gene of interest (CD274 or ASS1) with housekeeping beta-actin assay (for normalization). The CD274 probe was labeled with FAM (assay name Hs.PT.58.4665575), the ASS1 probe was labeled with Hex (assay name Hs.PT.56a.2920438) and the beta-actin probe was labeled with Cy5 (assay name Hs.PT.39a.22214847). Multiplexing did not affect assay performance - each of the above assays performed similarly when run as a singleplex or as a multiplex of beta-actin with either CD274 or ASS1. The qPCR was conducted in an ABI 7500 real time PCR system with the following program: 1 cycle at $50^{\circ} \mathrm{C}$ for 2 min, 1 cycle at $95^{\circ} \mathrm{C}$ for $10 \mathrm{~min}$ and 40 cycles of $15 \mathrm{sec}$ at $95^{\circ} \mathrm{C}$ followed by $1 \mathrm{~min}$ at $60^{\circ} \mathrm{C}$.

Control reactions without reverse transcriptase or a template were included to verify absence of genomic DNA or template contamination. Samples were run in duplicate during the qPCR step.

\section{Western blotting}

Cells were lysed in RIPA buffer supplemented with protease inhibitors. Lysate protein concentrations were determined by BCA assay and $\sim 20 \mu \mathrm{g}$ of protein was loaded for each sample onto $4-12 \%$ Tris-glycine polyacrylamide gels, two identical gels were used - one was stained with Simply Blue to confirm the protein amount loaded and another was transferred onto PVDF membrane with iBlot Western Blotting System (ThermoFisher Scientific). The membranes were blocked with 5\% non-dry milk-TBST and probed with primary antibodies (anti-ASS1 mAb or GAPDH mAb) followed by incubation with secondary goat anti-mouse IgG antibody conjugated 
with HRP. Detection was conducted with SuperSignal West Femto maximum sensitivity substrate and both the blots and stained protein gels were imaged on a BioRad's ChemiDoc Imager and band intensities were quantified using Image Lab software.

\section{In vivo studies}

$5 \times 10^{\wedge} 5$ B16-F10 cells were implanted subcutaneously into the right flank of C57BL/6 mice in 0.1 $\mathrm{mL}$ PBS. Animals were randomized into two groups - four mice into the control group and six mice into the ADIPEG 20 treatment group. The day after tumor inoculation and again 6 days later ( 7 days post tumor implantation) the control animals were injected intramuscularly with vehicle (PBS) and mice in the experimental group were injected intramuscularly with $12 \mathrm{mg} / \mathrm{kg}$ of ADI-PEG 20, both in a fixed $40 \mu \mathrm{L}$ total volume. Animals were euthanized on Day 7 after the last treatment (14 days post tumor implantation) and their tumors were excised. Tumors tissues were preserved in $4 \%$ paraformaldehyde solution for at least 24 hours and then embedded into paraffin.

IHC staining was performed at Zyagen: after deparaffinization, sections were boiled in $10 \mathrm{mM}$ citrate buffer under pressure for 5 minutes and after cooling down, sections were blocked with $5 \%$ BSA in PBS for 2 hours. Sections were then incubated with anti-CD3 mAb diluted $1: 100$ in $1 \% \mathrm{BSA}$ in PBS at $4{ }^{\circ} \mathrm{C}$ in a humidified chamber. Secondary antibody, antirabbit donkey sera conjugated with Alexa-Fluor-488 was diluted 1:100. Sections were counterstained with DAPI for 2 minutes.

Tumor growth and survival studies were performed at Wuxi AppTec. Anti-mouse PD-1 and PD-L1 monoclonal antibodies were purchased from BioXcell.

C57BL/6J mice were inoculated subcutaneously at the right flank with $2 \times 10^{\wedge} 5 \mathrm{~B} 16 \mathrm{~F} 10$ tumor cells in $0.1 \mathrm{~mL}$ of PBS (containing $0.05 \mathrm{~mL}$ matrigel) The animals were randomized based on the body weight, and treatment was started the next day after the cell inoculation with $12 \mathrm{mg} / \mathrm{kg}$ of ADI-PEG $20 \mathrm{QWx} 2 \mathrm{IM}$, $10 \mathrm{mg} / \mathrm{kg}$ anti-mPD-1 Q2D IP, $12 \mathrm{mg} / \mathrm{kg}$ of ADI-PEG 20 QWx2 IM and $10 \mathrm{mg} / \mathrm{kg}$ anti-mPD-1 Q2D IP or vehicle (PBS) control.

Balb/c mice were inoculated subcutaneously at the right flank with $2 \times 10^{\wedge} 5 \mathrm{CT} 26$ tumor cells) in $0.1 \mathrm{~mL}$ of PBS. Ten days after the tumor implantation the mice were randomized into four groups based on the tumor size and treated with $12 \mathrm{mg} / \mathrm{kg}$ of ADI-PEG 20 BIWx $5 \mathrm{~W}$ IM, 10 $\mathrm{mg} / \mathrm{kg}$ anti-mPD-L1 Q2D x 5W IP, $12 \mathrm{mg} / \mathrm{kg}$ of ADI-PEG $20 \mathrm{IM}$ BIWx $5 \mathrm{~W}$ and $10 \mathrm{mg} / \mathrm{kg}$ anti-mPD-L1 IP Q2D x 5W or vehicle (PBS) control.

Tumor size was measured in two dimensions using a caliper, and the volume was expressed in $\mathrm{mm}^{3}$ using the formula: $\mathrm{V}=0.5 \mathrm{a} \times \mathrm{b}^{2}$ where $\mathrm{a}$ and $\mathrm{b}$ are the long and short diameters of the tumor, respectively.

\section{Statistical analysis}

One-way ANOVA was performed to compare different treatments using GraphPad.

\section{ACKNOWLEDGMENTS AND FUNDING}

We thank Wes Sisson and Richard Showalter for making ADI-PEG 20 and mutant ADI-PEG 20, Richard Hickey for measuring arginine and citrulline levels and Jim Thomson for the critical review of the manuscript.

\section{CONFLICTS OF INTEREST}

All authors are employed by Polaris Pharmaceuticals and have options of Polaris Pharmaceuticals stock.

\section{REFERENCES}

1. Qiu F, Huang J, Sui M. Targeting arginine metabolism pathway to treat arginine-dependent cancers. Cancer Lett. 2015; 364:1-7.

2. Stasyk OV, Boretsky YR, Gonchar MV, Sibirny AA. Recombinant arginine-degrading enzymes in metabolic anticancer therapy and bioanalytics. Cell Biol Int. 2015; 39:246-52.

3. Phillips MM, Sheaff MT, Szlosarek PW. Targeting argininedependent cancers with arginine-degrading enzymes: opportunities and challenges. Cancer Res Treat. 2013; 45:251-62.

4. Feun L, You M, Wu CJ, Kuo MT, Wangpaichitr M, Spector S, Savaraj N. Arginine deprivation as a targeted therapy for cancer. Curr Pharm Des. 2008; 14:1049-57.

5. Feun L, Savaraj N. Pegylated arginine deiminase: a novel anticancer enzyme agent. Expert Opin Investig Drugs. 2006; 15:815-22.

6. Feun LG, Kuo MT, Savaraj N. Arginine deprivation in cancer therapy. Curr Opin Clin Nutr Metab Care. 2015; 18:78-82.

7. Patil MD, Bhaumik J, Babykutty S, Banerjee UC, Fukumura D. Arginine dependence of tumor cells: targeting a chink in cancer's armor. Oncogene. 2016; 35:4957-72.

8. Haines RJ, Pendleton LC, Eichler DC. Argininosuccinate synthase: at the center of arginine metabolism. Int $\mathrm{J}$ Biochem Mol Biol. 2011; 2:8-23.

9. Peranzoni E, Marigo I, Dolcetti L, Ugel S, Sonda N, Taschin E, Mantelli B, Bronte V, Zanovello P. Role of arginine metabolism in immunity and immunopathology. Immunobiology. 2007; 212:795-812.

10. Rodriguez PC, Ochoa AC. Arginine regulation by myeloid derived suppressor cells and tolerance in cancer: mechanisms and therapeutic perspectives. Immunol Rev. 2008; 222:180-91.

11. Bronte V, Zanovello P. Regulation of immune responses by L-arginine metabolism. Nat Rev Immunol. 2005; 5:641-54. 
12. Raber P, Ochoa AC, Rodríguez PC. Metabolism of L-arginine by myeloid-derived suppressor cells in cancer: mechanisms of $\mathrm{T}$ cell suppression and therapeutic perspectives. Immunol Invest. 2012; 41:614-34.

13. Rath M, Müller I, Kropf P, Closs EI, Munder M. Metabolism via Arginase or Nitric Oxide Synthase: Two Competing Arginine Pathways in Macrophages. Front Immunol. 2014; 5:532.

14. Delage B, Fennell DA, Nicholson L, McNeish I, Lemoine NR, Crook T, Szlosarek PW. Arginine deprivation and argininosuccinate synthetase expression in the treatment of cancer. Int J Cancer. 2010; 126:2762-72.

15. Albina JE, Caldwell MD, Henry WL Jr, Mills CD. Regulation of macrophage functions by L-arginine. J Exp Med. 1989; 169:1021-9.

16. Bansal V, Rodriguez P, Wu G, Eichler DC, Zabaleta J, Taheri F, Ochoa JB. Citrulline can preserve proliferation and prevent the loss of CD3 zeta chain under conditions of low arginine. J Parenter Enteral Nutr. 2004; 28:423-430.

17. Fletcher M, Ramirez ME, Sierra RA, Raber P, Thevenot P, AlKhami AA, Sanchez-Pino D, Hernandez C, Wyczechowska DD, Ochoa AC, Rodriguez PC. L-Arginine depletion blunts antitumor $\mathrm{T}$ cell responses by inducing myeloid-derived suppressor cells. Cancer Res. 2015; 75:275-83.

18. Rodriguez PC, Quiceno DG, Ochoa AC. L-arginine availability regulates T-lymphocyte cell-cycle progression. Blood. 2007; 109:1568-73.

19. Rodriguez PC, Hernandez CP, Morrow K, Sierra R, Zabaleta J, Wyczechowska DD, Ochoa AC. L-arginine deprivation regulates cyclin D3 mRNA stability in human T cells. by controlling HuR expression. J Immunol. 2010; 185:5198-204.

20. Zea AH, Rodriguez PC, Culotta KS, Hernandez CP, DeSalvo J, Ochoa JB, Park HJ, Zabaleta J, Ochoa AC. L-Arginine modulates CD3zeta expression and $\mathrm{T}$ cell function in activated human T lymphocytes. Cell Immunol. 2004; 232:21-31

21. Rodriguez PC, Zea AH, DeSalvo J, Culotta KS, Zabaleta J, Quiceno DG, Ochoa JB, Ochoa AC. L-arginine consumption by macrophages modulates the expression of CD3 zeta chain in T lymphocytes. J Immunol. 2003; 171:1232-9.

22. Gazzola GC, Franchi R, Saibene V, Ronchi P, Guidotti GG. Regulation of amino acid transport in chick embryo heart cells, I: adaptive system of mediation for neutral amino acids. Biochim Biophys Acta. 1972; 266:407-421.

23. Hyatt SL, Aulak KS, Malandro M, Kilberg MS, Hatzoglou M. Adaptive regulation of the cationic amino acid transporter-1 (Cat-1) in Fao cells. J Biol Chem. 1997; 272:19951-19957.

24. Aulak KS, Liu J, Wu J, Hyatt SL, Puppi M, Henning SJ, Hatzoglou M. Molecular sites of regulation of expression of the rat cationic amino acid transporter gene. J Biol Chem. 1996; 271:29799-29806.
25. Aulak KS, Mishra R, Zhou L, Hyatt SL, de Jonge W, Lamers W, Snider M, Hatzoglou M. Post-transcriptional regulation of the arginine transporter Cat-1 by amino acid availability. J Biol Chem. 1999; 274:30424-30432.

26. Tarasenko TN, Gomez-Rodriguez J, McGuire PJ. Impaired $\mathrm{T}$ cell function in argininosuccinate synthetase deficiency. $\mathrm{J}$ Leukoc Biol. 2015; 97:273-8.

27. Han RZ, Xu GC, Dong JJ, Ni Y. Arginine deiminase: recent advances in discovery, crystal structure, and protein engineering for improved properties. Appl Microbiol Biotechnol. 2016; 100:4747-60.

28. Burrows N, Cane G, Robson M, Gaude E, Howat WJ, Szlosarek PW, Pedley RB, Frezza 4, Ashcroft M, Maxwell PH. Hypoxia-induced nitric oxide production and tumour perfusion is inhibited by pegylated arginine deiminase (ADI-PEG20). Sci Rep. 2016; 6:22950.

29. Kelly MP, Jungbluth AA, Wu BW, Bomalaski J, Old LJ, Ritter G. Arginine deiminase PEG20 inhibits growth of small cell lung cancers lacking expression of argininosuccinate synthetase. Br J Cancer. 2012; 106:324-32.

30. Hasan AG, Lehe C, Ahmad R, Dermime S. Therapeutic targeting of B7-H1 in breast cancer. Expert Opin Ther Targets. 2011; 15:1211-1225.

31. Mittendorf EA, Philips AV, Meric-Bernstam F, Qiao N, Wu Y, Harrington S, Su X, Wang Y, Gonzalez-Angulo AM, Akcakanat A, Chawla A, Curran M, Hwu P, et al. PD-L1 expression in triple-negative breast cancer. Cancer Immunol Res. 2014; 2:361-370.

32. Tsai WB, Aiba I, Long Y, Lin HK, Feun L, Savaraj N, Kuo MT. Activation of Ras/PI3K/ERK pathway induces c-Myc stabilization to upregulate argininosuccinate synthetase, leading to arginine deiminase resistance in melanoma cells. Cancer Res. 2012; 72:2622-33.

33. Soliman H, Khalil F, Antonia S. PD-L1 expression is increased in a subset of basal type breast cancer cells. PLoS One. 2014; 9:e88557.

34. Chen J, Feng Y, Lu L, Wang H, Dai L, Li Y, Zhang P. Interferon- $\gamma$-induced PD-L1 surface expression on human oral squamous carcinoma via PKD2 signal pathway. Immunobiology. 2012; 217:385-93.

35. Mandai M, Hamanishi J, Abiko K, Matsumura N, Baba T, Konishi I. Dual Faces of IFN $\gamma$ in Cancer Progression: A Role of PD-L1 Induction in the Determination of Pro- and Antitumor Immunity Clin Cancer Res. 2016; 22; 2329-34.

36. Gowrishankar K, Gunatilake D, Gallagher SJ, Tiffen J, Rizos H, Hersey P. Inducible but not constitutive expression of PD-L1 in human melanoma cells is dependent on activation of NF- $\kappa$ B. PLoS One. 2015; 10:e0123410.

37. Munder $M$, Schneider $H$, Luckner $C$, Giese $T$, Langhans CD, Fuentes JM, Kropf P, Mueller I, Kolb A, Modolell M, Ho AD. Suppression of T-cell functions by human granulocyte arginase. Blood. 2006; 108:1627-34. 
38. Geiger R, Rieckmann JC, Wolf T, Basso C, Feng Y, Fuhrer T, Kogadeeva M, Picotti P, Meissner F, Mann M, Zamboni N, Sallusto F, Lanzavecchia A. L-arginine modulates $\mathrm{T}$ cell metabolism and enhances survival and anti-tumor activity. Cell. 2016; 167:829-842.

39. Rapovy SM, Zhao J, Bricker RL, Schmidt SM, Setchell KD, Qualls JE. Differential requirements for L-citrulline and L-arginine during antimycobacterial macrophage activity. J Immunol. 2015; 195:3293-300.

40. Holtsberg FW, Ensor CM, Steiner MR, Bomalaski JS, Clark MA. Poly(ethylene glycol) (PEG) conjugated arginine deiminase: effects of PEG formulations on its pharmacological properties. J Control Release. 2002; 80:259-71.
41. Bomalaski JS, Ivett JL, Vegarra M, Holtsberg FW, Ensor CM, Clark MA. Comparative toxicity of arginine deiminase formulated with poly(ethylene glycol) 5000 or 20,000 and the effects of arginine. Preclinica. 2003; 1:284 293.

42. Fultang L, Vardon A, De Santo C, Mussai F. Molecular basis and current strategies of therapeutic arginine depletion for cancer. Int J Cancer. 2016; 139:501-9. 